\title{
elyra
}

\section{Quase-evento: sobre a estoricidade da experiência literária ${ }^{1}$}

\section{Alexandre Nodari}

UFPR

Resumo: Partindo da definição de Barbara Smith da poesia como uma enunciação fictícia, historicamente indeterminada, pretende-se pensar o que (não-)acontece quando se performa aqui-e-agora essa enunciação. Nesse sentido, trata-se de esboçar uma ontologia, não do objeto literário, mas da experiência literária, ou seja, focando no encontro entre o a-histórico fictício e o presente histórico: o que esse contato faz, o que esse toque produz, que experiência, para onde (que tempo e que lugar) ela não cessa de nos enviar, e de onde vem esse envio?

Palavras-chave: quase-evento, estoricidade, performance

Abstract: If we take poetry as, according to Barbara Smith, a fictive utterance, historically undeterminated, what can be said to happen when that utterance is performed here-and-now? Answering this question can lead us to an ontology of literary experience (but not of the literary object), focused on the encounter between the a-historical space of fiction and the historical present: what does this encounter do, which experience does it produce, to where (which time and place) it doesn't cease to send us, and where does it come from?

Keywords: quasi-event, storicity, performance 
For poetry makes nothing happen: it survives In the valley of its making where executives Would never want to tamper, flows on south From ranches of isolation and the busy griefs, Raw towns that we believe and die in; it survives, A way of happening, a mouth.

W.H. Auden

O quase-acontecer: a repetição do que não terá acontecido? Eduardo Viveiros de Castro Escrever é tantas vezes lembrar-se do que nunca existiu. Como conseguirei saber do que nem ao menos sei? assim: como se me lembrasse. Com um esforço de "memória"” como se eu nunca tivesse nascido. Nunca nasci, nunca vivi: mas eu me lembro, e a lembrança é em carne viva.

Clarice Lispector

\section{Encenunciação}

Cinquenta anos atrás, concomitantemente à difusão do conceito e da prática da performance artística, Barbara Smith $(1968,1971)$ chamava a atenção para um fato que, talvez devido à sua obviedade, nunca foi plenamente explorado em toda sua profundidade, a saber, que aquilo que é fictício em um texto literário não são necessariamente o narrador, os personagens, os cenários, os diálogos, em suma, os enunciados literários, mas a própria enunciação (o seu próprio acontecimento: “Tudo que o poeta 'diz' pode ser verdadeiro, mas o seu dizê-lo não é" (Smith 1968: 15). A poesia, enquanto nome de tal "enunciação ficta", seria, assim, uma modalidade peculiar de discurso, um "discurso encenado", para usar o termo de Rainer Warning (1980), que se diferencia das demais modalidades discursivas não do ponto de vista formal, mas por encená-las. Desse modo, se ainda devemos falar em 
mimese (em sentido amplo e não de mera repetição), o que é mimetizado na poesia não são ações, fatos, pessoas, estados internos, mas o próprio referir-se a eles, a própria alusão, i.e., o discurso sobre eles, a própria experiência verbal (assim como, na pintura, o mimetizado não seriam objetos, nem sensações, mas perspectivas). Ao contrário daquilo que Smith chama de "enunciação natural", a enunciação "fictícia", ou "mimética", não constitui um evento histórico (embora o enunciado, aquilo que se enuncia possa sê-lo), ou seja, jamais aconteceu enquanto uma ocorrência singular situada em um contexto espaço-temporal determinado - o que a impede de ser inserida em uma cadeia unívoca de sentido. "Historicamente indeterminada", ou mesmo "a-histórica", a enunciação literária se assemelharia ao roteiro de uma peça ou a uma partitura musical; fora da história, ela demandaria ser performada, a começar pelo seu autor:

O texto de um poema nos informa [...] como produzir o ato verbal que ele representa. [...] o texto de qualquer poema deve ser interpretado, em primeiro lugar, como, de fato, uma partitura ou direções de palco para a performance de um ato puramente verbal que existe somente ao ser performado. Um poema nunca é dito, nem pelo próprio poeta. Ele é sempre re-citado; pois qualquer que seja a sua relação com as palavras que o poeta poderia ter falado, ele, enquanto poema, não tem nenhuma ocorrência histórica primeira (Smith 1971: 273).²

Para dar um exemplo propositalmente extremo: Brás Cubas nunca enunciou suas Memórias póstumas: estas constituem uma enunciação fictícia que precisa ser, a cada vez, encenada pelos leitores (e antes deles, pelo seu "autor", Machado de Assis), que demanda o que sugiro chamar, para marcar uma indiscernibilidade entre enunciação e encenação, uma encenunciação. É por jamais ter ocorrido de uma vez por todas que uma enunciação fictícia não cessa de recorrer, de ocorrer a cada vez que é performada (pela sua composição, pela sua leitura, mesmo que silenciosa, pelas suas traduções e adaptações): é por não ter acontecido em nenhum espaço e em nenhum tempo que ela não cessa de acontecer, sem que seu acontecer cesse, se dê de uma vez por todos, em qualquer espaço e em qualquer tempo - a suposta universalidade e eternidade dos textos literários deriva disso. Mas o que acontece quando o não-acontecido acontece? O que acontece quando o nem-aqui nemagora a-histórico é performado aqui-e-agora, no presente? O que acontece quando a enunciação jamais dita é enunciada, ou seja, quando se dá a enunciação do não-dito? 


\section{O que é fazer um programa?}

Barbara Smith (1968: 9), apoiando-se em Valéry, concebe a relação entre a enunciação fictícia e sua performance em termos de potencialidade e ato. O texto literário, análogo, como vimos, a uma partitura ou a um roteiro, seria uma "estrutura linguística" e não um "evento linguístico" (Smith 1973: 274), ou melhor, a estrutura que possibilita, instrui e informa a sua eventualização (enquanto representação). Todavia, por um lado, o próprio contexto em que Smith insere essa distinção, a saber, o da composição do poema, já aponta para a sua precariedade: "O que o poeta compõe como texto", diz ela, "não é um ato verbal mas sim uma estrutura linguística que se torna, ao ser lida ou recitada, a representação de um ato verbal" (ibidem). Se, como vimos, o poema, "enquanto poema, não tem nenhuma ocorrência histórica primeira", isto implica que a composição é já uma re-citação, dobrando a eventualização sobre a estrutura e vice-versa? Por outro lado, devemos ter em mente que toda atualização de um texto literário é também uma atuação, ou ainda, que toda performance (leitura) literária, como lembra Iser (1993: 236-248) é um performativo, que não designa o dado ou remete a uma referência, mas suplementa o dado criando a referencialidade, figurando o não-dito a partir (para além) do dito textual: a dimensão performativa (e não simplesmente repetidora) é mobilizada e se torna possível e necessária não só por aquilo que o texto diz (as "instruções" para a sua execução), como também, e especialmente, pelo que deixa de dizer, pelas suas entrelinhas. Nesse sentido, a performance de um texto literário não pode se caracterizar pela mera realização de um possível já dado pelo texto. Enquanto "estrutura linguística", o texto literário deve abrir-se à sua própria variação (estrutural): "Uma peça", afirma Edward Bond, "possui um valor permanente não porque diga algo que é verdadeiro para todos os tempos, mas porque é uma estrutura em que novas verdades podem ser inseridas. Uma peça é permanente porque ela muda e só porque ela muda" (apud Azevedo 2016: 213; tradução modificada). Um duplo movimento pode nos fazer entender melhor como, desse modo, a relação potência-ato ou estrutura-evento deve ser repensada para que sirva de chave à compreensão da performance de um texto. O primeiro deslocamento é em direção ao vocabulário da performance em sentido estrito, no qual, como sugere Eleonora Fabião (2008: 237), o análogo a um roteiro ou a uma partitura se chamaria "programa": 
Chamo as ações performativas programas, pois, neste momento, esta me parece a palavra mais apropriada para descrever um tipo de ação metodicamente calculada, conceitualmente polida, que em geral exige extrema tenacidade para ser levada a cabo, e que se aproxima do improvisacional exclusivamente na medida em que não seja previamente ensaiada. Performar programas é fundamentalmente diferente de lançar-se em jogos improvisacionais. O performer não improvisa uma idéia: ele cria um programa e programa-se para realizá-lo (mesmo que seu programa seja pagar alguém para realizar ações concebidas por ele ou convidar espectadores para ativarem suas proposições). Ao agir seu programa, desprograma organismo e meio.

Ao retomar a proposição de Fabião para pensar a literatura, João Camillo Penna enfatizou a abertura à exterioridade, à experiência, que um paralelo entre texto/programa e leitura/performance implica: "o performativo e a performance vão invariavelmente envolver essa articulação com um fora".$^{3}$ Trata-se, assim, de conceber o texto-programa não como uma série de instruções imperativas (que permitem a variação, mas não variam elas mesmas) para uma representação, e sim como um "motor de experimentação" (na definição deleuzo-guattariana de programa que inspira Fabião) para a performance, que pode retroagir sobre o próprio programa (a estruturalização do evento implicaria a eventualização da estrutura). E aqui se insere o outro movimento, o de pensar a ressonância dessa concepção de programa com a expressão "fazer um programa", no uso que ela possui no jargão da prostituição. Nela, o fazer (a poiesis) que está em jogo é, para dizer o mínimo, ambígua, ambivalente, anfíbia: por um lado, pode indicar a concretização, realização de um programa, enquanto roteiro pré-estabelecido; por outro, pode designar igualmente a confecção, elaboração de um tal programa/roteiro a ser efetuado: tanto evento quanto estrutura, tanto atualização quanto criação de uma possibilidade. Evidentemente, os dois sentidos podem se sobrepor, e é isso que interessa: assim, diacronicamente, o programa elaborado, acordado, será depois performado (a não ser que a performance fracasse ou seja infeliz, para jogar com as expressões de Austin); e, do mesmo modo, mas sincronicamente, a realização de um programa pré-estabelecido pode dar lugar à sua reelaboração em ato, caso no qual o programa (o possível) é feito nas duas acepções de fazer, e isso no próprio ato de seu fazer (que, portanto, não coincide consigo mesmo). Ou seja, se fazer um programa sobrepõe (dobra) a elaboração (potência) sobre a realização (ato) e vice-versa, nesta dobra é o próprio fazer que não coincide consigo, tornando-se duplo: não só fazer alguma coisa, mas 
também elaborar sobre este fazer, refazê-lo no ato mesmo de sua feitura. Embora a analogia, a meu ver frutífera de um ponto de vista extra-moral, pudesse se estender (a prática e a implicação de corpos envolvida; a relacionalidade que, dobrando um sobre o outro, torna, no limite, indiscerníveis ator e receptor, atividade e passividade; a duplicidade entre fingimento - estranhamento - e "realidade" - identificação -, a saber, o duplo sentido de atuação), importa sublinhar aqui que a poiesis artística me parece da mesma ordem do fazer um programa. Texto e performance não se relacionam como potência e ato, estrutura e evento, fora e dentro da história, mas por meio de um fazer específico, uma experiência especial que dobra um sobre o outro, modificando a ambos e a seu estatuto.

\section{Quase-evento}

"Quando lemos ou ouvimos um poema", diz Smith (1968: 16), "somos confrontados com a performance de um ato de fala, não com o ato em si". Agora, o que diferencia a performance de um ato do próprio ato? Se estamos corretos, dificilmente conseguiríamos achar uma distinção formal, pois a diferença reside na produção de uma diferença do evento em relação a si mesmo, uma tomada de distância ontológica, advinda do modo de experimentá-lo, a experiência de sua dobradura, que o faz dobrar-se sobre si mesmo, de maneira que ele não coincide plenamente consigo mesmo. Por isso, inspirando-nos em uma formulação de Eduardo Viveiros de Castro (2009), segundo a qual o "quase acontecer algo [... é] um modo de acontecer outra coisa que aquele algo", talvez possamos caracterizar a performance de uma enunciação literária como um quase-evento. ${ }^{4}$ "Quase" em dois sentidos, conexos entre si: 1) o primeiro, de uma proximidade ontológica que, porém, importa uma distância ainda que infinitesimal, pois nenhuma performance realiza plenamente e de uma vez por todas a enunciação fictícia, convertendo-a em um evento histórico determinado e definitivo, fazendo da estrutura um evento pleno: esta passagem, que se realiza a cada performance, é também, a cada vez e no mesmo gesto, adiada, como se a eventualização do texto poético fosse o limite (assintótico) ao qual tendesse, sem jamais alcançar, toda performance, toda leitura - não um limite externo e negativo, mas um limite interno, constitutivo, positivo; não um limite que não pode ser transgredido, mas um que, ao contrário, impele, é motor; 2) o segundo é a acepção etimológica de quase, como se (quasi é 
uma contração de quam si, e quam, por sua vez, o é de quo modo, como, ao modo de), que remete à encenação, a algo que está ao modo de outro, o que deve ser lido em seu sentido radical de sobreposição (dobradura) paradoxal do contraditório, pois toda encenação implica não só a dramatização de um outro, como também do próprio paradoxo de ser ao mesmo tempo a si mesmo e ao outro5: como afirma Jankélévitch (1995: 250-1), o filósofo que mais se deteve sobre o "quase", esse não designa um misto de ser ou não ser, "não é um terceiro princípio, mas ele próprio é a suspensão do princípio e de sua consequência, o princípio da disjunção". Na encenação, no quase-evento, o princípio da não-contradição é suspenso, mas não abolido: estrutura e evento não se fundem, mas se sobrepõem. Por isso, poderíamos desfazer a dicotomia da frase acima citada de Barbara Smith, reescrevendo-a do seguinte modo: quando lemos ou ouvimos um poema, somos confrontados com a performance de um ato de fala, que, ao mesmo tempo, é e não é o ato de fala em si. ${ }^{6} \mathrm{O}$ quase-evento nomeia esse evento que não coincide consigo mesmo, esse encontro oblíquo que é também um desencontro, quando algo acontece e não acontece ao mesmo tempo em suma, uma distorção da eventualidade, um evento distorcido ou contorcido, para usar a terminologia de Lucius Provase (2016). Sempre que um evento (um ato, um gesto, uma enunciação, uma cena) é experimentado como não coincidindo consigo mesmo, com seu contexto, com seu sentido (seja por excesso seja por falta), e que essa não-coincidência se torne a própria matéria e a própria forma do evento, isto é, o (re)configure, estamos diante de um quase-evento, de uma experiência que na cultura ocidental moderna chamamos de artística. ${ }^{7}$ O quase-evento coloca em cena outra cena (ou, melhor, uma cena outra, o outro da cena): a do acontecer do próprio acontecimento, a da sua feitura - pois a poesia, afirma Jankélévitch (1995: 260), é a "arte de apreender ou captar a flagrância oportuna do [...] fazendo-se em vias de se fazer". Assim, uma performer que se corta está, no gesto mesmo de se cortar, criando uma distância (ontológica) em relação a ele, no próprio ato de sua realização: com sua performance, coloca em questão o que é um corte, o que é um corpo, o que é a violência, o que é um gesto, o que é uma performance, e, obviamente, o que é arte. O mesmo se passa com a leitura de um texto literário, com a performance de uma enunciação fictícia: a enunciação desta por meio dos leitores (e mesmo, como vimos, pelo seu "autor"), a encenunciação, coloca em cena, em questão, o que é uma enunciação, como 
se dá, quem e quantos falam, qual a relação entre palavras e coisas, entre o dizer e o dito, o que é um contexto, o que é (um)a história - e isso, no próprio gesto da enunciação. ${ }^{8}$

\section{Estoricidade}

Retomando a oposição de Smith entre eventos históricos e eventos a-históricos, podemos agora pensar o que acontece quando eles se (des)encontram na performance de um texto literário, e como esse encontro pode reconfigurar a oposição. O que estamos chamando de quase-evento parece constituir uma posição espaço-temporal oblíqua, em que o nem-aqui e nem-agora (o fora do espaço-tempo) ficcional se encontra, sem se confundir, com (se dobra sobre, se sobrepõe ao) o aqui e agora do ato da leitura. Nesse sentido, o que se torna presente na performance de uma ficção não é (apenas) algo que está fora da história (do contexto) e que de repente a adentraria, mas a própria exterioridade à história: o que se torna presente é um deslocamento, uma diferença em relação à presença plena de um ato repleto de sentido, totalmente configurado historicamente (ou melhor, experimentado como tal). É essa diferença que marca a diferença, que (re-)configura o evento em quase-evento. Trata-se, assim, de um deslocamento ontológico em relação ao próprio presente, a presença do extemporâneo, que jamais pode estar plenamente presente - pois a sua presença consiste naquele deslocamento. Um exemplo talvez nos ajude a entender melhor. Os mitos, como se sabe, se situam no começo dos tempos, explicam a origem do mundo, das coisas, e do próprio tempo, o que transparece nos marcadores temporais míticos: "no princípio", "no começo dos tempos", "antigamente". Todavia, apesar disso, os mitos - tanto os "nossos", judaico-cristãos ou greco-romanos, quanto os não ocidentais - não cessam de ser contados no presente não apenas para explicar a gênese imemorial, mas para, como uma espécie de dobra espaço-temporal, falar diretamente do momento atual e mesmo intervir nele (para o bem ou para o mal, para além do bem e do mal). Um lugar comum consiste em encarar esse procedimento afirmando que os mitos são parábolas, com o que podemos concordar, desde que não tomemos as parábolas em sentido parabólico e sim como autênticas parábolas espaço-temporais, em que o começo dos tempos (e do tempo) se encontra com o aqui-e-agora. Os marcadores temporais míticos servem, assim, para produzir uma indeterminação histórica, uma contra-determinação 
histórica, para colocar o mundo atual entre parênteses (para falar de outra coisa, e fazer a coisa outra nos falar - eis o procedimento parabólico), apenas para melhor incidir nele, coincidir com ele. Ou, para dizê-lo de outra maneira, os marcadores temporais míticos servem para marcar que o que está sendo dito e o seu dizer não aconteceram de uma vez por todas, mas estão acontecendo agora, a cada vez que os mitos são performados. Os mitos são inatuais, jamais foram atuais, mas estão in-scritos em toda atualidade (cabendo ao gesto de contar o seu ex-crever, isto é, expor a relação do atual com algo que difere de si). Por isso é que os mitos não se situam (só) em um tempo original, mas em uma temporalidade originária, que não só é o começo dos tempos, como também não cessa de originar o presente - de fora dele: a temporalidade originária é aquela a partir da qual o presente está sempre se (re)fazendo, saindo fora dos seus eixos. O mesmo tanto, creio, se poderia dizer das ficções literárias, não só porque elas, como parábolas, incidem no presente dando a ver a sua sombra, a sua diferença consigo mesmo (pensemos no uso - diagnóstico ou prognóstico - que fazemos dos adjetivos "kafkiano" ou "quixotesco", por exemplo), mas porque elas também se situam nessa temporalidade originária que não cessa de se encontrar com o nosso tempo a cada vez que são performadas. De modo semelhante aos marcadores temporais míticos, o "Era uma vez" dos contos de fada constitui, assim, um performativo: não se refere a uma vez passada, mas produz essa vez a cada vez que é enunciada. Por isso, poderíamos dizer que "tal vez" seja o dêitico espaço-temporal da ficção, indicando tanto "aquela vez", ou seja a efetividade fática criada pelo pretérito na ficção (Hamburger 2013) quanto "talvez", a dúvida, que é, em si, dúplice: tanto em relação à plenitude do presente e da sua presença, pois que chocado com uma sombra originária, quanto em relação à distância daquilo que está fora do tempo e não deveria nos afetar. Nesse sentido, para dar conta da performance literária, da encenunciação, as expressões mobilizadas por Smith, "a-historicidade" ou "indeterminação histórica", parecem insuficientes, pois remetem apenas à enunciação fictícia e não à relação entre essa e o evento da sua performance (caracterizada como representação daquele ato historicamente inexistente). Talvez o melhor fosse, retomando um famoso adágio de Guimarães Rosa (“A estória, em rigor, deve ser contra a História"), falar em estoricidade ou contra-historicidade. ${ }^{9}$ Pois a ausência de contexto histórico das enunciações literárias, sua a-historicidade, implica 
uma transhistoricidade, sua indeterminação histórica implica que elas podem ser sobredeterminadas pelas múltiplas leituras, pelos múltiplos presentes. A estoricidade, ou contrahistoricidade remete a uma temporalidade da experiência literária que consiste num encontro, a partir (ex-) da história, com algo que está fora (ex-) da história, contra-histórico, no sentido de que não é histórico, mas não cessa de se encontrar com a história. ${ }^{10}$

\section{Decontextualização}

La literatura no es agotable, por la suficiente y simple razón de que um solo libro no lo es. El libro no es un ente incomunicado: es una relación, es un eje de innumerables relaciones. Una literatura difiere de otra, ulterior o anterior, menos por el texto que por la manera de ser leída

Jorge Luis Borges

Foquemos a estoricidade a partir do outro polo, a saber, não mais a partir do encontro da história com aquilo que está fora dela, e sim do desencontro da história em relação a si mesma - o que equivale, à primeira vista, à passagem do enfoque da recepção e leitura à da criação e autoria, distinção que cumpre colocar em cheque. O processo de ficcionalização (ou estoricização) de uma enunciação pode ser melhor entendido não como uma abolição do contexto, da referência e do sentido (sempre históricos, demasiado históricos), mas antes como sua suspensão: “Não há literatura”, diz Derrida (2014: 70), "sem uma relação suspensa com o sentido e com a referência. Suspensa quer dizer suspensão, mas também dependência, condição, condicionalidade. Em sua condição suspensa, a literatura apenas pode exceder a si mesma". ${ }^{11}$ Ou seja, a enunciação literária jamais coincide com seu(s) contexto(s) (o de sua publicação, os de suas recepções, o do ambientação de seu enredo, os que o texto retoma por meio de alusões, citações, referências), embora não se situe desde sempre, a priori, fora dele(s). Pois é como se o caráter poético, literário ou artístico da enunciação fictícia derivasse do fato de ela ser, como a citação para Walter Benjamin $(2006: 500,517)$ "arrancad[a] de seu contexto", fazendo da literatura algo próximo àquela "arte de citar sem usar aspas" que ele vislumbrou como objetivo do trabalho das 
Passagens. Isso, porém, quer dizer também que a enunciação literária guarda uma relação com o contexto da qual é arrancada: trata-se de um movimento para fora (ex-) dele (da história, sentido, ou referência), mas a partir dele (ex-), uma saída do espaço-tempo a partir de certo espaço-tempo. Agora, não se trata de uma mera descontextualização que, reduzindo-se a uma distância espaço-temporal ou contextual, pudesse ser revertida por meio de uma recontextualização que esgotasse seu sentido ao encaixá-lo em seu contexto adequado (como as leituras sociológicas ou historicistas pretendem), mas de um deslocamento violento que se faz e produz uma distância (uma não-coincidência ou um desencontro) de ordem ontológica, e, portanto, não colmável de modo definitivo, entre a enunciação fictícia e seu(s) contexto(s), entre a a-historicidade e a historicidade, e que sugerimos chamar de decontextualização, para marcar um sentido forte e inspirando-nos na ideia de "decolonização". Pensar em termos de decontextualização e não de mera descontextualização permite entender como essa não-coincidência da enunciação literária com um contexto determinado é o que possibilita a sua encenunciação (a sua performance, a sua leitura) em múltiplos contextos, sem, porém, que jamais adira definitivamente a nenhum deles: a suposta universalidade e eternidade dos textos literários de que falamos acima. Suposta, pois não se trata de fato de universalidade e de eternidade: as enunciações literárias não se situam em todo espaço e em todo tempo, mas em nenhum espaço e em nenhum tempo (a-historicidade) - e, por isso, podem ser situadas em qualquer espaço e qualquer tempo (estoricidade). Ou melhor: em quase qualquer tempo e qualquer espaço. Pois há pelo menos uma limitação temporal óbvia: um poema, por exemplo, não pode ser performado antes de ser "composto" (encenado pela primeira vez pela voz, escrita ou imaginação daquele que chamamos de seu autor), mas só a partir de então, a partir do contexto do qual foi decontextualizado. Possivelmente devido à herança romântica, ou ao reforço que ela efetuou da figura do criador demiurgo, tende-se a atribuir o movimento de decontextualização, de saída da história, a um gesto soberano e ex nihilo do artista, mesmo que pela mobilização de certas propriedades formais da linguagem: poderíamos pensar, por exemplo, na recomendação aristotélica do uso de "vocábulos peregrinos" (metáforas, ou seja, desvios semânticos, desvios de sentido, palavras estrangeiras, barbarismos), ou então no "estranhamento" de Chklovsky, como formulações de modos de produzir 
decontextualizações. Todavia, o exemplo mais explícito, e, portanto, mais acabado, de decontextualização, o ready-made de Duchamp, mostra que não é (ou não é só) no polo do criador que devemos buscar a fonte (o trocadilho é inevitável) desse arrancar do contexto: a proverbial reação diante do mictório (ou de outros exemplos da arte moderna e contemporânea), "qualquer um faria isso" (cuja importância me foi salientada por Clarissa Comin em um texto inédito e capital sobre a enunciação literária), ao colocar em cena e em questão a autoria e o fazer artístico, mostra que a decontextualização não deve ser compreendida como um ato gerador de um objeto ou fato ontologicamente diferente daqueles históricos, pois consiste antes de tudo em certa experiência, certa relação com as coisas e o contexto, com as coisas e seus contextos, um corpo-a-corpo com eles, ou seja, que a criação é, no limite, indistinguível da recepção (o que, aliás, é atestado na tradição literária ocidental pelas constantes atribuições da fala do poeta a um dom externo, e mesmo extrahumano: o furor divino, as musas, o gênio, a floresta de correspondências, etc.). "Qualquer um faria isso" quer dizer, portanto, que não há nenhuma diferença essencial entre artista (autor) e espectador (leitor) - “Um poema nunca é dito, nem pelo próprio poeta. Ele é sempre re-citado" -, como também, e isso é crucial, que na experiência artística (literária) não faz sentido distinguir o momento do desencontro em relação à história (criação) daquele do encontro com o a-histórico (recepção), ou seja, diferenciar o momento em que um evento sai da história daquele em que esse evento se encontra com ela, pois o que se encontra é justamente o des-encontro, essa dis-junção ou dobra: o quase-evento da performance, e a experiência estórica que ela instaura. Mas insistir que "qualquer um faria isso", repitamos, quer dizer ainda que a distinção entre eventos históricos e estóricos não diz respeito a fatos ontologicamente diferentes (no caso da literatura, a enunciação; pense-se no conhecido episódio da transmissão radiofônica de $A$ guerra dos mundos, de Orson Welles), mas a experiências, essas sim ontológica e não só fenomenologicamente distintas, em relação a eles. A existência de museus, galerias, do marcador de "ficção", em suma, da série de convenções, cambiantes e precárias, que nos fazem experimentar algo como "arte", apontam tanto para a institucionalização e mesmo aprisionamento da experiência artística em heterotopias e heterocronias quanto para a precariedade da sua distinção com o não artístico (se é preciso avisar o que é arte é porque não há algo que seja em si artístico), e, 
portanto, a importância da recepção na produção do movimento de decontextualização, da mudança do estatuto de um evento. $E$, de fato, a estoricidade de uma enunciação muitas vezes deriva do modo como ela é recebida por leitores, muitas vezes (e por isso mesmo) distantes no espaço-tempo daquele: é o que acontece com muitos textos que hoje tomamos como literários, poéticos, fictícios, etc., mas que não eram concebidos como tais em seu "contexto de origem". Trata-se, nesse caso, de uma distância espaço-temporal (uma descontextualização) que se transforma em uma distância ontológica, de modo que um evento é retroativamente estoricizado. ${ }^{12}$

Mas não é só isso. Bento Prado Jr. (2000: 193), em sua leitura de "O recado do morro", de Guimarães Rosa, identificara um fenômeno interior à trama da novela que podemos expandir para fora dela e numa direção teorética: é "como se o ruído", diz ele, "que ameaça a propagação da mensagem com sua entropia tivesse o efeito exatamente inverso ao esperado: a mensagem, progressivamente deformada, aproxima-se cada vez mais de sua verdade". Baseando-nos na teoria da ressonância de Dimock (1997), segundo a qual o acúmulo de ruídos derivados das inúmeras leituras em diversos contextos de um texto literário, as suas ressonâncias, podem nos fazer "ouvir melhor", "ler melhor", o que torna a sua "ontologia instável", podemos dizer que, analogamente ao recado do morro rosiano, a estoricidade (o caráter fictício) da enunciação é variável, sendo historicamente aumentada, diminuída, alterada ou potencializada ao longo da história da sua recepção (mesmo involuntariamente: pensemos em quantas alusões contextuais são decontextualizadas com o passar do tempo e o acúmulo de leituras convergentes ou divergentes, ou nas variações a que estão sujeitos os campos semânticos de palavras e enunciados, ou do próprio processo de significação). ${ }^{13}$ Tais ressonâncias ou ruídos, portanto, não nos afastariam entropicamente de sua verdade histórica ou estórica, mas, ao contrário, nos aproximariam tendencialmente (mas nunca completamente) do seu recado.

Desse modo, como estamos vendo, toda a-historicidade possui sua historicidade, outro motivo pelo qual preferimos falar em estoricidade ou contra-historicidade: no encontro estórico, na parábola espaço-temporal, não é apenas o presente (a história) que é afetada pelo seu exterior - este também se modifica. Assim como o estatuto estórico de certa enunciação tem sua história, também as seguidas performances, ao menos as públicas, 
de um texto (publicações, edições, críticas, traduções, adaptação, etc.) podem (não sem conflitos) "aderir" à ficção, ou seja, as inúmeras performances e contextos podem perfazer o texto, passando a ser fios que o compõem ou que o enovelam, de modo que uma leitura não-mediada, virgem das camadas históricas da recepção, de Dom Quixote, por exemplo, é impossível. Nesse sentido, se podemos concordar com a tese de Kate Hamburger (2013: 96, 115) de que as ficções se passam em uma espécie de presente sem passado e sem futuro, isto é, estão sempre acontecendo a cada vez que são lidas ou contadas, pois um texto ficcional "não narra sobre pessoas e coisas, mas narra as pessoas e coisas [...], as produz pela narração", a caracterização dessa temporalidade como um "presente estacionário" parece ignorar que tal presente fora de toda linha temporal está também sempre mudando, variando com suas seguidas performances históricas (e isso em cascata, ou de forma indireta: pensemos em como as alterações, por exemplo, no modo de conceber a antiguidade greco-romana alteram também as alusões, referências ou retomadas dela em textos literários - e vice-versa, evidentemente). Por isso, preferimos falar em temporalidade originária (ou, como pretendo fazer em outro lugar, em espaço-tempo transicional), a "névoa não-histórica" de que falavam Deleuze e Guattari (1997: 131), e que é composta (ou carregada) de múltiplos espaço-tempos. A encenunciação de um texto literário, o encontro entre a história e aquilo que está fora dela, em suma, a experiência da estoricidade, é a de uma sobreposição simultânea e muitas vezes inconsciente de contextos, em que, como vimos, os tempos estão constantemente se (re)fazendo, variando: sair da história implica experimentar muitas historicidades ao mesmo tempo, implica adentrar não a ausência da história mas a sua multiplicidade e indeterminação, rearranjando, refazendo a ela e a seu próprio espaço-tempo - ou seja, permite fazer a experiência de uma "variação dos contextos", como vem pensando Roberto Zular (2013). Para colocar de outra maneira o movimento de mão dupla que viemos descrevendo: se a enunciação fictícia não tem um contexto histórico determinado com o qual pode formar uma cadeia de sentido, é preciso (re)criar o contexto para que ela faça sentido. É verdade que, diante de uma enunciação qualquer, necessitamos sempre complementar o seu sentido (concatená-la a uma teia de significação), mas, no caso de uma enunciação fictícia, é preciso mais: é preciso suplementar o seu sentido - toda enunciação fictícia demanda um "suplemento originário" [para invocar 
novamente Derrida (2006: 383)], mostrando assim como toda constituição de sentido é suplementar. Grosso modo, essa tarefa seria infinita, pois exigiria criar um mundo inteiro, composto de inúmeros espaços-tempos outros em que essa enunciação fizesse sentido. Mas é evidente que buscamos realizar esse encargo, esse dar sentido ao que não tem sentido, a partir do nosso sentido, do nosso contexto, da nossa experiência, embora isso não seja sem consequências: se à enunciação fictícia transporta-se parabolicamente (metáfora) o nosso contexto, a recíproca também é verdadeira, a saber, que a enunciação fictícia - e a sua estoricidade (as suas multiplicas historicidades) - se transporta(m) ao nosso contexto: determinar um contexto ao que não tem contexto determinado implica indeterminar o contexto de nosso ato, o nosso contexto. Dar sentido a partir do aqui e agora da encenação, da performance, implica dotar o aqui e agora de outro sentido, mudar o seu sentido, na medida em que algo exterior lhe perfura, Ihe desloca. "Qualquer um faria isso": de fato, qualquer um pode fazê-lo, pode fazer essa experiência, mas, para tanto, precisa querer, se implicar no fazer - implica o (re)fazer. ${ }^{14} \mathrm{O}$ espaço literário é o de uma multiplicidade de espaços-tempos que rearranjamos (e nos rearranjam) a cada performance. Performar a literatura é des-encadear o sentido do nosso espaço-tempo, permitindo a sua - e também a do espaço-tempo estórico - refazenda.

\section{Refazenda}

Ao definir a encenação como uma "iniciação ao distanciamento", Warning (1980: 52) propõe que não se veja na literatura a desativação total dos usos pragmáticos do discurso (o seu caráter tão reivindicado de "inutensílio", para usar a famosa expressão de Leminski), ou seja, um desuso ou não-uso (uma linguagem não utilitária), mas antes um re-utilizar a linguagem: "O discurso ficcional é discurso re-utilizável". Creio que aqui se esboça um programa para repensar o literário em sua indissociabilidade com a performance, para abordar a poiesis, o fazer nela implicado, fugindo da alternativa infernal entre, por lado, a linguagem como mimese e representação, e, por outro, uma abolição do uso cotidiano pragmático dela. O que implica pensar a poesia como uma re-citação, uma reutilização, uma reciclagem da linguagem - tarefa politicamente tão necessária no cenário atual de superprodução, mesmo semiótica (cf. Durão 2008), e, portanto, de lixo, material e verbal? O 
que implica pensar a poesia sem referência a uma origem, a um original, sem, por isso, perder de vista não o fazer (sentido), mas o refazer (sentido), essa experiência de originariedade que a arte comporta ${ }^{15} \mathrm{O}$ que significa, por fim, pensar a poesia não como mero desvio ou creatio ex nihilo, mas como (re)creatio ex possibile, criação que parte do (ex-) possível, rumo a um fora dele (o poeta como reciclador das palavras e discursos, que Ihes dá um novo sentido a partir de outros neles soterrados, redobrando-os, desdobrando-os sobre os seus usos comuns)? Inserir a performance nesse programa (concebê-la já na origem, na gênese, na "composição" poética - a composição já como uma performance, ou seja, como uma re-citação -, em um gesto que tanto borra a origem quanto a torna iterável, convertendo-a na experiência do originário, do que não cessa de dar origem sem jamais fazê-lo de uma vez por todos) me parece um bom caminho para (re)começar a ver na poesia não um fazer autônomo de obras, e sim uma constante refazenda da experiência, não uma produção de acontecimentos, mas um modo peculiar de (re)experimentá-los, em nossa língua, em nossa boca, em nosso corpo: um quase-evento estórico. 


\section{Notas} ${ }^{1}$ Uma versão preliminar desse texto foi apresentada no Seminário Performar a literatura. Pesquisas para uma
redefinição do literário (UFPR; 8 e 9 de dezembro, 2016). Um dos motores foi certa divergência produzida no Simpósio homônimo que coordenei junto com Flávia Cera e João Camillo Penna no XV Encontro da ABRALIC (Rio de Janeiro, 2016), quando, nos debates, utilizei a expressão "quase-evento" para caracterizar a experiência literária, que aqui tento expor na forma de roteiro prévio de uma série de questões que ainda devem ser desdobradas. Cabe salientar que utilizo alternadamente como sinônimos, e de modo consciente, os termos "acontecimento" e "evento" (e expressões derivadas, como "quase-acontecimento" e "quase-evento"), cruzando a terminologia adotada por Eduardo Viveiros de Castro em "A morte como quase-acontecimento" e a de Barbara Smith, de quem tomo - e posteriormente problematizo - a distinção entre eventos historicamente determinados e historicamente indeterminados. Por fim, agradeço àqueles que contribuíram para a formulação da presente versão do texto, por meio de objeções, questões, sugestões, etc., em especial João Camillo Penna, Lucius Provase, Tiago Guilherme Pinheiro e os meus alunos de graduação e pós-graduação do segundo semestre de 2016, com os quais pude debater algumas das hipóteses e argumentos aqui esboçados.

${ }^{2}$ Agradeço a Guilherme Bernardes pelo auxílio em algumas traduções desse texto de Barbara Smith. Eventuais erros devem-se a modificações que introduzi.

${ }^{3}$ A citação provém do texto que Camillo Penna apresentou no simpósio "Performar a literatura", durante o XV Encontro da ABRALIC (Rio de Janeiro, UERJ, 2016), intitulado “Pragmática e poética do programa”, e ainda não publicado.

${ }^{4}$ Como pretendo demonstrar em outra oportunidade, não se trata apenas de um empréstimo terminológico, mas de uma afinidade mais estrutural entre a teoria do perspectivismo ameríndio e o conceito de ficção que venho tentando construir, proximidade que se deixa ler nas entrelinhas da própria conferência de Viveiros de Castro, da qual tomo emprestada a expressão ("A morte como quase-acontecimento"), quando ele afirma que a "quasidade é o modo de existência por excelência da morte, a narrativa: a morte é algo sobre o que você fala". Cf., provisoriamente Nodari 2015.

${ }^{5}$ Veja-se esta passagem de $A$ idéia do teatro, de Ortega y Gasset (1991: 39): “Pois bem, o mesmo acontece no teatro, que é o 'como se' e a metáfora corporificada - portanto, uma realidade ambivalente que consiste em duas realidades - a do ator e a da personagem do drama que mutuamente se negam. É preciso que o ator deixe durante um momento de ser o homem real que conhecemos e é preciso também que Hamlet não seja efetivamente o homem real que foi. É mister que nem um nem outro sejam reais e que incessantemente se estejam desrealizando, neutralizando para que só fique o irreal como tal, o imaginário, a pura fantasmagoria." E esta outra, de Iser (que parece mobilizar vocabulário e perspectiva semelhantes a de Ortega), que propõe relacionarmos a leitura à esta atuação (em inglês, performance) do ator, invocando o mesmo Hamlet: "In this respect the required activitiy of the recipient resembles that of an actor, who in order to perform his role must 
use his thoughts, feelings, and even his body as an analogue for representing something he is not. In order to produce the determinate formo $f$ na unreal character, the actor must allow his own reality to fade out. At the same time, however, he does not know precisely who, say, Hamlet it, for one cannot properly identify a character who has never existed. Thus role-playing endows a figment with a sense of reality in spite of its impenetrability which defies total determination. The reader finds himselh in much the same situation. To imagine what has been stimulated by aesthetic semblance entails placing our thoughts and feelings at the disposal of an unreality, bestowing on it a semblance of reality in proportion to a reducing of our own reality. For the duration of the performance we are both ourselves and someone else" (Iser 1993: 244).

${ }^{6}$ Isso é o que se convencionou chamar de "ontologia dual" da arte. Cf., por exemplo, Pavel 1986: 54-57. Outro modo de abordar a mesma questão é pelo olhar da pragmática; no discurso ficcional, afirma Warning (1980: 43), nos encontramos diante de uma situação paradoxal (ou de uma dupla situação, tratando-se de um discurso duplamente situado): "the speech situation extricated itself from any immediate determination by the use situation, without this use situation simply disappearing. What occurs here is much more a schism in the situation, so that an internal speech situation stands in opposition to an external recepction situation. Fictional discourse is thus determined pragmatically by the simultaneity of two situations, each of which is bound to its own deictic system. Now this is a structure well known to the pragmatic theory of human communication. For being caught it simultaneously within two situations leads the subject into those contradictory transactional rules which have been described as the pragmatic paradox of the 'double bind'. One can logically solve such paradoxes by placing one side of the contradiction on a higher hierarchical level, thus making the contradiction meaningless. For those who find themselves caught in the paradox, however, such a solution is not possible unless a game situation provides them with a way out".

7 É evidente, como mostrou Derrida (1991: 11-37) em sua leitura dos atos de fala de Austin, que este diferimento em relação à presença, o caráter anfíbio da iterabilidade (repetição e diferença, estrutura e evento) de toda escrita (no sentido amplo, de grafema) é a condição de possibilidade de todo evento, de toda experiência, a marca inscrita em qualquer acontecimento (no caso que nos interessa aqui: em qualquer enunciação). A meu ver, retomando outro texto de Derrida (2014: 71), a diferença do que estamos chamando de "quase-evento" consiste em que, nele, tal não-coincidência (não-presença) se torna a questão, o problema, a dificuldade: "Nessa mesma perspectiva, ainda temos dificuldade de definir a questão da literatura [...]. A literatura 'é' o lugar ou a experiência dessa 'dificuldade'". Para uma leitura recente da performatividade austiniana que prolonga a crítica de Derrida em outra direção, cf. Cassin (2010).

8 "A poesia e a literatura têm como traço comum, mesmo que sempre de maneira desigual e diferente, suspender a ingenuidade tética da leitura transcendente. Isso também dá conta da força filosófica dessas experiências, uma força de provocação para pensar a fenomenalidade, o sentido ou o objeto, até mesmo o ser como tal; uma força que é pelo menos potencial, uma dynamis filosófica, passível, no entanto, de se desenvolver somente na resposta, na experiência da leitura, pois não se encontra escondida no texto como 
uma substância. Poesia e literatura proporcionam ou facilitam o acesso 'fenomenológico' àquilo que faz de uma tese uma tese como tal. Antes de ter um conteúdo filosófico e de ser ou de defender essa ou aquela 'tese', a experiência literária, como escritura ou como leitura, é uma experiência 'filosófica' neutralizada ou neutralizante, na medida em que permite pensar a tese; é uma experiência não tética da tese, da crença, da posição, da ingenuidade, do que Husserl chamou de 'atitude natural'. A conversão fenomenológica do olhar, a 'redução transcendental', que ele recomendava, talvez seja a condição mesma (não digo a condição natural) da literatura. Mas é verdade que, levando essa proposição às últimas consequências, ficaria tentado a dizer (como o fiz noutro lugar) que a linguagem fenomenológica, na qual estou apresentando assim as coisas, termina por ser desalojada de suas certezas (presença a si da consciência transcendental absoluta ou do cogito indubitável etc.), e desalojada precisamente pela experiência extrema da literatura, ou mesmo tão simplesmente da ficção e da língua" (Derrida, 2014:67).

9 A inspiração para a escolha do termo "estoricidade" vem de um trabalho inédito de Rondinelly Gomes Medeiros sobre algumas novelas de Corpo de baile, no qual ele aventa a ideia de uma "transformação estórica" operando.

10 A escolha por abordar os mitos e aproximar deles o que convencionamos chamar de ficção literária, passando por cima de certas diferenças essenciais, é uma estratégia consciente que já tentei justificar em outros lugares, lançando mão e desenvolvendo o conceito de ficção de Juan José Saer, que a toma como uma “antropologia especulativa” (cf. Nodari, 2015). Apesar do que argumenta Lévi-Strauss sobre a descontinuidade na passagem do mito ao romance, a meu ver, a máxima borgeana de que "en el principio de la literatura está el mito, y asimismo en el fin" continua válida. Um romance recente que gira em torno dessa questão, bem como de outras aqui abordadas é Rio acima, de Pedro Cesarino (2016).

${ }^{11}$ Não derivaria desse "ser ou estar-suspenso da literatura", como Derrida a caracteriza, o suspense que parece marcar a Stimmung de toda leitura de um texto literário, a expectativa mas também o receio, sempre presentes mas sempre frustrados, de que o sentido último e a referência plena subitamente emerjam?

${ }^{12}$ A distância histórica foi recorrentemente concebida como condição e pretexto para a fabulação. Assim, por exemplo, para Torquato Tasso, segundo Stierle, (2006: 48), "A história não permite nenhuma ficção à medida que trata de fatos ainda recentes; quanto mais, entretanto, ela recua, tanto mais oferece ao poeta matéria para sua ficção, pois os conhecimentos transmitidos são tão vagos que o poeta pode ativá-los". Trata-se evidentemente, do topos - estoricamente verdadeiro - de que, quanto mais recuamos na história, mais nos aproximamos do mito.

13 "As candidates for nonintegral survival, the diachronic phenomena called literature bear the generic mark of incompleteness (...). Given a domain so deficient in boundaries, the literary can make no claim to an indwelling identity. The literary, in other words, is not an attribute resident in a text, but a relation, a form of engagement, between a changing object and a changing recipient, between a tonal presence and the way it is differently 
heard over time. In a provisional definition, then, the literary might refer to that which resonates for readers past, present, and future. This definition is ruthlessly idealizing -ruthlessly because it makes a nonentity out of what it idealizes. For since readers past, present, and future are not the same reader, a text can remain literary only by not being the same text. It endures by being read differently. Over time, not only does the membership of the literary domain change, but also each text becomes different from itself, suffers a semantic sea change, acquires a freight of new meaning. (...) A literary text is a prime example of an object that is not individuated as a fixed set of attributes within fixed coordinates. Indeed, the continual emergence of interpretive contexts suggests that the attributes of a text also continually emerge. Not a finished product, a text is the incomplete expression of a finite language user; moving beyond that finite individual, it becomes a collective potentiality, a force of incipience commensurate with the incipience of humanity. It is this collective dimension of a text that makes its temporal trajectory unforeseeable. And insofar as this trajectory is describable at all, perhaps it is best described as a continuum, registering both extension and transit, changes in time and in attributes. Such a continuum, such extension through motion, makes diachronism an interpretive necessity" (Dimock 1997: 1064).

${ }^{14}$ Sugerimos, nesse ponto, a introdução de um erro de tradução na página final do célebre "A morte do autor", de Barthes, vertendo "quelqu'un" não por "alguém”, mas por "qualquer" (o que não está longe de um acerto do ponto de vista etimológico), reinserindo nessa figura indeterminada que é o leitor enquanto posição (diante) do texto (o leitor implícito de Iser, o ponto nodal das inúmeras relações para Borges) a implicação subjetiva, a dimensão do desejo, do querer, tão cara a Barthes: "um texto é feito de escrituras múltiplas, oriundas de várias culturas e que entram umas com as outras em diálogo, em paródia, em contestação: mas há um lugar onde essa multiplicidade se reúne, e esse lugar não é o autor, como se disse até o presente, é o leitor: o leitor é o espaço mesmo onde se inscrevem, sem que nenhuma se perca, todas as citações de que é feita uma escritura: a unidade do texto não está em sua origem, mas no seu destino, mas esse destino não pode mais ser pessoal: o leitor é um homem sem história, sem biografia, sem psicologia: ele é apenas esse qualquer [alguém - quelqu'un] que mantém reunidos em um único campo todos os traços de que é constituído o escrito" (Barthes 2004, 65). Sobre o “qualquer", cf. as páginas iniciais de Agamben, 1993.

${ }^{15}$ Talvez fosse essa experiência que os neoconcretos, Ferreira Gullar à frente, tinham em mente quando diziam conceber "a obra de arte nem como 'máquina' nem como 'objeto', mas como um quasicorpus", vendo como símile dela os "organismos vivos": "[a obra] está sempre se fazendo presente, está sempre recomeçando o impulso que a gerou e de que ela era já a origem. E se essa descrição nos remete igualmente à experiência primeira - plena - do real, é que a arte neoconcreta não pretende nada menos que reacender essa experiência." 


\section{Bibliografia}

Agamben, Giorgio (1993), A comunidade que vem, tradução de António Guerreiro, Lisboa, Editorial Presença.

Azevedo, Beatriz (2016), Antropofagia - palimpsesto selvagem, São Paulo, Cosac Naify.

Barthes, Roland (2004), O rumor da língua, tradução de Mario Laranjeira, 2. ed., São Paulo, Martins Fontes.

Benjamin, Walter (2006), Passagens, organização da edição brasileira por Willi Bolle, Belo Horizonte, Ed. UFMG/São Paulo, Imprensa Oficial do Estado de São Paulo.

Cassin, Barbara (2010), “A performance antes do performativo, ou a terceira dimensão da linguagem", tradução de Luana de Conto, Revista Letras, n. 82, 11-46.

Cesarino, Pedro (2016), Rio acima, São Paulo, Companhia das Letras.

Deleuze, Gilles / Félix Guattari (1997), O que é filosofia?, tradução de Bento Prado Jr. e Alberto Alonso Muñoz, 2. ed., Rio de Janeiro, Ed. 34.

Derrida, Jacques (2014), Essa estranha instituição chamada literatura, tradução de Marileide Dias Esqueda, Belo Horizonte, Ed. UFMG.

-- (2006), Gramatologia, tradução de Miriam Chnaiderman e Renato Janine Ribeiro, 2. ed., São Paulo, Perspectiva.

-- (1991), Limited Inc., tradução de Constança Marcondes Cesar, Campinas, Papirus.

Dimock, Wai Chee (1997), “A Theory of Resonance”, PMLA, v. 112, n. 5, 1060-1071.

Durão, Fábio Akcelrud (2008), “Da superprodução semiótica: caracterização e implicações estéticas", in A indústria cultural hoje, São Paulo, Boitempo, 39-48.

Fabião, Eleonora (2008), “Performance e teatro: poéticas e políticas da cena contemporânea", sala preta, n. 8, 235-246.

Hamburger, Käte (2013), A lógica da criação literária, tradução de Margot P. Malnic, São Paulo, Perspectiva. 
Iser, Wolfgang (1993), Prospecting: from reader response to literary anthropology, Baltimore, The John Hopkins University Press.

Jankélévitch, Vladimir (1995), Primeiras e últimas páginas, tradução de Maria Lúcia Pereira, Campinas, Papirus.

Nodari, Alexandre (2015), "A literatura como antropologia especulativa", Revista da ANPOLL, n. $38,75-85$.

Ortega y Gasset, José (1991), A ideia do teatro, tradução de J. Guinsburg, São Paulo, Perspectiva.

Pavel, Thomas (1986), Fictional worlds, Cambride, Harvard University Press. Prado Jr., Bento (2000), Alguns ensaios: filosofia, literatura, psicanálise, 2. ed., São Paulo, Paz e Terra.

Provase, Lucius (2016), Lastro, rastro e historicidades distorcidas: uma leitura dos anos 70 a partir de Galáxias, tese de doutorado, FFLCH/USP, <http://www.teses.usp.br/teses/disponiveis/8/8151/tde-16082016-150905/pt-br.php>.

Smith, Barbara (1968), Poetic Closure: A Study of How Poems End, Chicago, University of Chicago Press.

-- (1971), "Poetry as fiction", New Literary History, v. 2, n. 2, 259-281.

Stierle, Karlheinz (2006), A fiç̧ão, tradução de Luiz Costa Lima, Rio de Janeiro, Caetés.

Viveiros de Castro, Eduardo (2009), "A morte como quase-acontecimento", <http://www.institutocpfl.org.br/2009/10/16/integra-a-morte-como-quase-acontecimentoeduardo-viveiros-de-castro/>.

Warning, Rainer (1980), "Staged discourse: remarks on the pragmatics of fiction", Dispositio, v.5, n. 13/14, 35-44.

Zular, Roberto (2013), "Valéry e o Brasil ou a literatura comparada como produção de contexto", ponto-e-vírgula, n. 13, 49-65. 
Alexandre Nodari é professor do Departamento de Linguística e Literatura e dos Programas de Pós-Graduação em Letras e em Filosofia da Universidade Federal do Paraná (Brasil). Fundador e coordenador do species - núcleo de antropologia especulativa, foi editor da Cultura e Barbárie e do Sopro. 